\title{
KESEPADANAN TERJEMAHAN TRANSKRIP VIDEO DARI BAHASA INGGRIS KE BAHASA INDONESIA PADA MATA KULIAH MOVIE TRANSLATION (SUBTITLING)
}

\author{
Nurul Fitriani' ${ }^{1}$, Yoga Pratama $^{2}$, Kurnia Idawati ${ }^{3}$, Alia Afiyati ${ }^{4}$ \\ Universitas Darma Persada \\ E-mail: nurulfitriani0404@gmail.com
}

\begin{abstract}
Nowadays, people can easily access everything with one-click away. For example, when you want to read an article in foreign language which you are not familiar with, then you just need to open Google Translate and within seconds, you will get the translation of it. To deal with that reality, a translator has to differentiate himself from machine translation which is increasingly used by the public. Therefore, the translator is required to produce an equivalent and natural translation in the Target Language. This research aims to provide understanding of translation equivalence on video transcripts conducted by students in Movie Translation (Subtitling) course. This study uses qualitative approach, content analysis method, and purposive sampling to collect data. In short, there are two types of translation equivalence used by students, formal and dynamic. Formal equivalence focuses on the similarity of the form and meaning of the message from Source Language to Target Language, while dynamic one focuses on the naturalness of expression in the Target Language.
\end{abstract}

Keywords: equivalence, translation, transcript, video, subtitling.

\begin{abstract}
ABSTRAK
Di era serba digital saat ini, masyarakat begitu dengan mudah mengakses apapun hanya dengan satu klik saja. Sebagai contoh, ketika ingin me mbaca suatu tulisan dalam bahasa asing yang tidak kita kuasai, maka kita tinggal membuka Google Translate, dan dalam hitungan detik, sudah mendapatkan terjemahan dari tulisan tersebut. Dalam menghadapi realitas itu, maka seorang penerjemah tentu harus membuat dirinya berbeda dari mesin penerje mahan yang semakin banyak dan sering digunakan oleh masyarakat. Oleh karena itu, penerjemah pun dituntut untuk menghasilkan terjemahan yang sepadan dan alamiah di bahasa sasaran. Penelitian ini hadir un tuk memberikan pemahaman mengenai konsep kesepadanan terje mahan pada transkrip video yang dilakukan oleh mahasiswa di matakuliah Movie Translation (Subtitling). Penelitian ini menggunakan pendekatan kualitatif dengan metode analisis isi, dan teknik pengambilan data purposive sampling. Terdapat dua jenis kesepadanan yang digunakan oleh mahasiswa, formal dan dinamis. Kesepadanan formal berfokus pada kesamaan aspek bentuk dan isi pesan, sedangkan dinamis berfokus pada kewajaran ekspresi di bahasa sasaran.
\end{abstract}

Kata kunci: kesepadanan, terjemahan, transkrip, video, subtitling.

\section{PENDAHULUAN}

Pada masa di mana teknologi berkembang sangat pesat seperti saat ini, manusia mendapatkan berbagai akses kemudahan dalam melakukan apapun. Di Indonesia, misalnya, sejak maraknya penggunaan ponsel pintar atau smart phone, masyarakat seakan masuk ke dalam dunia baru yang sangat memudahkan kegiatan sehari-hari mereka. Apabila kita ingin menghubungi kerabat yang berbeda kota dan/atau negara, kita sudah tidak melulu bergantung pada komunikasi lewat telepon, melainkan juga bisa menggunakan fitur video call yang ditawarkan oleh

Cara men gutip: Fitriani, N., Pratama, Y., Idawati, K. \& Afiy ati, A. (2020). Kesepadanan Terjemahan Transkrip Video dari Bahasa Inggris ke Bahasa Indonesia pada Mata Kuliah Movie Translation (Subtitling). Inteligensi: Jurnal Ilmu Pendidikan, $3(2), 47-53$ 
berbagai aplikasi dalam ponsel pintar yang kita miliki. Apabila kita ingin mencari suatu informasi secara cepat, saat ini ini kita perlu lagi mencarinya di buku, cukup dengan sentuhan jari beberapa kali di layar ponsel pintar, maka kita akan terhubung dengan salah satu mesin pencari terbesar di dunia, Google. Setelah itu, apapun informasi yang ingin dicari, dapat kita akses dengan mudah dan cepat.

Begitu juga halnya ketika kita ingin membaca suatu tulisan dalam bahasa asing yang tidak kita kuasai sama sekali, masyarakat tidak perlu kecewa akan ketidakmampuan yang mereka miliki, karena Google Translate akan menerjemahkan dari satu bahasa ke bahasa lain dengan cepat dan mudah sehingga mereka pun bisa menikmati bacaan yang mereka sukai. Namun, suatu pertanyaan muncul dari adanya salah satu fitur dari Google bernama Google Translate tersebut. Bagaimana nasib penerjemah? Tentu saja, jawaban akan pertanyaan tersebut dapat bervariasi, bisa saja ada yang menganggap Google Translate dan/atau perangkat lunak penerjemahan lainnya sebagai hal yang lumrah karena kita tidak bisa menghindari kemajuan teknologi di abad 21 ini. Atau mungkin saja ada yang beranggapan bahwa hasil terjemahan yang menggunakan berbagai mesin penerjemahan adalah tidak dapat diandalkan dan dipertanggung jawabkan. Penerjemah semakin ditantang menghadapi kecanggihan dan "kepintaran" beragam mesin penerjemahan yang ada saat ini.

Catford (1965:20) menggunakan pendekatan kebahasaan dalam memandang penerjemahan. Ia berujar bahwa pesan dari teks sumber saat dialihkan ke teks sasaran haruslah sepadan. Kesepadanan dipandang sebagai suatu hal mutlak dilakukan oleh penerjemah apabila ingin hasil terjemahan yang ia buat berterima di pembaca sasaran. Pernyataan Catford di atas juga senada dengan pernyataan Nida \& Taber (1974:12) yang mengemukakan bahwa penerjemahan terdiri dari proses mereproduksi teks ke dalam bahasa sasaran yang sebisa mungkin memiliki kesepadanan yang berterima dan benar dari pesan yang terkandung dalam bahasa sumber, baik dalam aspek makna maupun dalam aspek gaya bahasanya.

Sehingga dapat dikatakan bahwa seorang penerjemah dituntut memiliki penguasaan gramatikal dan leksikal yang baik pada dua bahasa, sumber dan sasaran, serta penerjemah harus menempatkan kesepadanan makna sebagai prioritas utama agar pembaca bahasa sasaran dapat memahami maksud yang ingin disampaikan penulis teks. Suatu terjemahan dianggap berhasil apabila pesan, gagasan, pikiran, dan konsep yang ada dalam bahasa sumber dapat disampaikan ke dalam bahasa sasaran secara utuh. Menurut Hoed (2006:25), seorang penerjemah harus memahami bahasa sumber dan bahasa sasaran secara baik, dan juga latar belakang kebudayaan dari kedua bahasa tersebut. Lebih lanjut ia mengemukakan tiga kualitas yang setidaknya harus dimiliki oleh seorang penerjemah, yakni: 1) menguasai pengetahuan umum yang luas (dan pengetahuan khusus jika ia menerjemahkan secara teknis);2) memiliki kecerdasan memahami sebuah teks dan melihat secara cepat teks yang harus diterjemahkan; dan 3) memiliki kemampuan merekayasa bahasa agar menghasilkan terjemahan yang sepadan, 
akurat, dan berterima di pembaca bahasa sasaran.

Machali (2009:26) menambahkan bahwa melalui penerjemahan, seorang penerjemah menyampaikan kembali isi sebuah teks ke dalam bahasa lain. Penyampaian tersebut bukan sekadar mengganti belaka karena penerjemah pada dasarnya melakukan kegiatan komunikasi baru lewat hasil kegiatan komunikasi yang sudah ada (dalam bentuk teks), tetapi dengan memperhatikan aspek sosial dari bahasa sasaran. Salah satu keahlian yang harus dimiliki oleh penerjemah adalah menjaga keutuhan pesan dalam teks yang diterjemahkannya. Untuk melakukan itu, maka penerjemah harus memperhatikan kesepadanan makna dari bahasa sumber ke bahasa sasaran. Pesan yang terkandung dalam teks yang akan diterjemahkan harus dialihkan secara seimbang, sesuai, dan padan agar maksud yang ingin disampaikan oleh penulis teks tersebut dapat dipahami secara utuh oleh pembacanya.

Nord (1997:35-36) mendefinisikan kesepadanan sebagai suatu konsep yang bersifat statis dan berorientasi pada hasil yang menggambarkan hubungan nilai komunikasi yang setara antara dua teks, antara kata-kata, frasa, kalimat, struktur sintaksis, dan sebagainya. Nilai komunikasi yang dimaksud merujuk pada makna, konotasi stilistik, atau efek komunikatif dari pesan yang tertuang dalam teks. Nida, seperti dikutip dari Hatim dan Munday (2004:167), menjelaskan bahwa secara fundamental, ada dua jenis kesepadanan dalam penerjemahan, yaitu kesepadanan formal dan dinamis. Kesepadanan formal berfokus pada pesan dalam teks itu sendiri, baik dalam aspek bentuk, maupun aspek isi. Kemudian, kesepadanan dinamis berfokus pada makna yang ingin disampaikan oleh penulis teks sumber, dan juga jenis kesepadanan ini bertujuan melengkapi kewajaran ekspresi bagi pembaca bahasa sasaran, sehingga teks terjemahan menjadi alamiah, tidak terasa seperti "terjemahan" belaka.

Popovic dalam Bassnett (2002:33) membagi kesepadanan terjemahan ke dalam empat bagian, antara lain: 1) kesepadanan linguistik yang berorientasi pada kesamaan pada level linguistik bahasa sumber dan bahasa sasaran; 2) kesepadanan paradigmatik yang fokus terhadap unsur-unsur ekspresi paradigmatik; 3) kesepadanan stilistik yang berfokus pada kesepadanan fungsional dalam bahasa sumber dan bahasa sasaran dengan tujuan identitas ekspresif tapi pesannya tidak berubah; dan 4) kesepadanan tekstual yakni kesepadanan struktur sintagmatis dari sebuah teks. Sedangkan Koller seperti dikutip dari Munday (2008:47), mengemukakan lima jenis kesepadanan terjemahan, yakni: 1) kesepadanan denotatif yang berkaitan dengan kesepadanan isi ekstralinguistik dari suatu teks; 2) kesepadanan konotatif yang berhubungan dengan pemilihan leksikal; 3) kesepadanan teks normatif yang berhubungan dengan jenis teks; 4) kesepadanan pragmatik yang berorientasi kepada penerima teks atau pesan; dan 5) kesepadanan formal yang berkaitan dengan bentuk dan keindahan dalam teks.

Chen dikutip dari Senja (2015:33) mendefinisikan takarir (subtitling) sebagai suatu proses pengalihan informasi dan rekonstruksi informasi dari bahasa sumber ke dalam bahasa sasaran. Takarir dilakukan dengaN menyesuaikan ruang 
dari layar dan waktu saat pembicara berujar sesuatu. Kjaer dalam Senja (2015:33) juga mengungkapkan bahwa proses penerjemahan takarir membutuhkan langkah khusus, dan biasanya dikerjakan secara berkelompok karena ada sebagian yang mendengarkan bahasa sumber, ada yang menerjemahkan ke dalam bahasa sasaran, dan ada sebagian juga yang mengetik teks untuk dimasukkan ke dalam video. Lebih lanjut, Aveline (2015:25) mengutip pernyataan Gottlieb yang menjelaskan bahwa pada dasarnya terdapat dua kategori takarir yaitu intra-lingual dan inter-lingual. Intralingual subtitling berorientasi pada pemroduksian takarir dalam bahasa yang sama dan biasanya digunakan untuk pembelajar bahasa. Sedangkan interlingual subtitling merupakan pemroduksian takarir dari dua bahasa yang berbeda. Bernschütz dalam Aveline (2015:26) membagi proses takarir ke dalam tiga fase, antara lain: 1) transkrip bahasa sumber dibagi berdasarkan adegan dari video yang digunakan; 2) transkrip kemudian diterjemahkan ke dalam bahasa sasaran; dan 3) dilakukan proses timing untuk menyesuaikan bagian terjemahan dari video yang digunakan.

\section{METODE PENELITIAN}

Pendekatan penelitian yang digunakan adalah pendekatan kualitatif dengan metode analisis isi yang bersifat deskriptif guna mendapatkan pendalaman analisis secara komprehensif terkait kesepadanan terjemahan dari bahasa Inggris ke bahasa Indonesia. Sumber data penelitian ini adalah transkrip video yang telah diterjemahkan oleh mahasiswa Jurusan Bahasa dan Kebudayaan Inggris pada matakuliah Movie Translation (Subtitling), di Universitas Darma Persada.
Pengambilan data dilakukan secara bertujuan menggunakan teknik purposive sampling dimana peneliti memilih dan menggunakan data yang sesuai dengan tujuan penelitian. Analisis data yang dilakukan pada penelitian ini antara lain: 1) peneliti memilih data dari terjemahan transkrip video dari bahasa Inggris ke bahasa Indonesia; 2) peneliti mempelajari struktur gramatikal, konteks bahasa, dan budaya secara rinci dan mendalam sehingga peneliti lebih yakin perihal kesepadanan terjemahan yang ditemukan; dan 3) peneliti menjabarkan hasil analisis kesepadanan terjemahan.

\section{HASIL DAN PEMBAHASAN}

Berikut adalah beberapa hasil temuan kesepadanan terjemahan transkrip video yang ditemukan beserta pembahasannya:

Tabel 1. Taylor Swift Barbra Walters Interview

\begin{tabular}{ll}
\hline \multicolumn{1}{c}{ Teks Sumber } & \multicolumn{1}{c}{ Teks Sasaran } \\
(TSu) & \multicolumn{1}{c}{ (TSa) } \\
\hline "If you haven't & "Jika kalian masih \\
guessed her name by & belum dapat \\
now, you are clearly & menebak namanya, \\
living under a very & kalian jelas tinggal di \\
large rock." & dalam gua." \\
\hline
\end{tabular}

Teks sumber di atas diambil dari video berjudul "Taylor Swift Barbra Walters Interview, Barbra Walters Most Fascinating People” (ABC News, 2014). Di video tersebut, penyanyi Taylor Swift berbagi kisah dengan Barbara Walters perihal musik pop dan karir bernyanyinya. Secara garis besar, datum pertama ini dikatakan sebagai sepadan karena penerjemah takarir mengalihkan pesan dari bahasa sumber ke dalam bahasa sasaran secara utuh. Frasa "living under a very large rock" di bahasa sumber ternyata 
tidak diterjemahkan secara harfiah di bahasa sasarannya. Merujuk pada tipe kesepadanan terjemahan menurut Nida, penerjemah memilih kesepadanan dinamis dalam menerjemahkan frasa tersebut. Sehingga, frasa "living under very large rock" diterjemahkan menjadi "tinggal di dalam gua" di bahasa sasaran, karena penerjemah ingin menghadirkan kewajaran ekspresi di bahasa Indonesia. Biasanya masyarakat Indonesia, khususnya remaja, menggunakan istilah "tinggal di dalam gua" merujuk kepada orang yang ketinggalan informasi terbaru, karena mereka diibaratkan terlalu lama berada di dalam gua sehingga tidak tahu informasi terkini tentang suatu hal.

Tabel 2. Taylor Swift Barbra Walters Intervie w II

\begin{tabular}{|c|c|}
\hline $\begin{array}{l}\text { Teks Sumber } \\
\text { (TSu) }\end{array}$ & $\begin{array}{l}\text { Teks Sasaran } \\
\text { (TSa) }\end{array}$ \\
\hline $\begin{array}{l}\text { "One magazine } \\
\text { headline said at best, } \\
\text { Taylor Swift is the } \\
\text { music industry," }\end{array}$ & $\begin{array}{l}\text { "Salah satu topik } \\
\text { utama suatu majalah } \\
\text { mengatakan Taylor } \\
\text { Swift menguasai } \\
\text { industri musik," }\end{array}$ \\
\hline
\end{tabular}

Teks ke-dua masih diambil dari wawancara Barbara Walters dengan Taylor Swift. Kali ini, Walters mengungkapkan bagaimana media menjuluki $S$ wift sebagai penguasa industri musik. Tentu hal itu bukanlah berlebihan, karena apabila melihat fakta prestasi yang dicapai oleh Swift dalam karirnya sebagai penyanyi, julukan seperti itu dianggap wajar saja. Setiap kali Swift merilis lagu atau bahkan album, maka langsung menempati posisi atas berbagai chart musik.

Penerjemah telah mengalihkan pesan teks sumber ke dalam teks sasaran secara sepadan. Kali ini, ditemukan juga kesepadanan dinamis yang digunakan oleh penerjemah. Hal tersebut dapat dilihat pada klausa "Taylor Swift is the music industry" yang diterjemahkan menjadi "Taylor Swift menguasai industri musik" di bahasa sasarannya.

Penerjemah tidak menerjemahkan klausa itu secara harfiah seperti "Taylor Swift adalah industri musik" untuk menghindari ambiguitas bahasa.

Tabel 3. Ew with Jimmy Fallon and Channing Tatum

\begin{tabular}{ll}
\hline \multicolumn{1}{c}{$\begin{array}{c}\text { Teks Sumber } \\
\text { (TSu) }\end{array}$} & \multicolumn{1}{c}{$\begin{array}{c}\text { Teks Sasaran } \\
\text { (TSa) }\end{array}$} \\
\hline "Alright, moving & "Baiklah, selanjutnya \\
on, Susie, are you & Susie, apakah kamu \\
still taking dance & masih ikut kelas \\
lesson?" & menari?" \\
"Yeah, I am like, & "Ya, kamu tahulah, \\
you know, Itake a & aku mengambil kelas \\
hip hop hawk class & hip hop hawk di hari \\
on like Saturday, it & Sabtu, begitulah." \\
is like whatever." & \\
\hline
\end{tabular}

Dialog ke-tiga diambil dari video berjudul "Ew with Jimmy Fallon and Channing Tatum" (The Tonight Show Starring Jimmy Fallon, 2012), dan berdurasi 3 menit 43 detik. Di video ini, tampak Jimmy Fallon sebagai pembawa acara Late Night Show bermain sketsa dengan bintang tamu aktor Channing Tatum. Di situ tampak Fallon berperan sebagai Sara dan Tatum sebagai Susie. Terjemahan percakapan di datum ke-tiga ini pada dasarnya adalah sepadan, karena tentu saja penerjemah, yang dalam hal ini adalah mahasiswa, mampu mengalihkan pesan dari bahasa Inggris ke bahasa Indonesia. Apabila merujuk pada jenis kesepadanan menurut Nida seperti dikutip dari Hatim dan Munday (2004:167), maka penerjemah menggunakan jenis kesepadanan formal dimana penerjemah berorientasi pada pesan dalam teks itu sendiri, dan mempertahankan aspek bentuk dan isi dari ujaran yang diterjemahkan. 
Suatu dialog diambil dari video yang berjudul "Ew with Jimmy Fallon and Channing Tatum (Late Night Show with Jimmy Fallon)". Kali ini masih melanjutkan percakapan perihal kelas hip hop, Sara, yang diperankan oleh Jimmy Fallon, meminta Susie (Channing Tatum) untuk menunjukkan gerakan hip hop yang telah ia pelajari di kelas tari.

Tabel 4. Ew with Jimmy Fallon and Channing Tatum

\begin{tabular}{ll}
\hline \multicolumn{1}{c}{$\begin{array}{c}\text { Teks Sumber } \\
\text { (TSu) }\end{array}$} & \multicolumn{1}{c}{$\begin{array}{c}\text { Teks Sasaran } \\
\text { (TSa) }\end{array}$} \\
\hline "Hip hop is cool! & "Hip hop itu keren! \\
Can you show me & Bisakah kamu \\
some of their & menunjukkan \\
moves?" & beberapa \\
& gerakannya?" \\
"Ew! Yeah, of & "Ew! Ya, tentu saja!" \\
course." & \\
\hline
\end{tabular}

Penerjemah mampu menerjemahkan percakapan di datum ke-empat ini dengan sepadan, dengan menggunakan kesepadanan formal. Tidak ada perubahan bentuk yang signifikan kecuali kata " $m e$ " di teks sumber yang tidak diterjemahkan ke dalam teks sasarannya.

Tabel 5. Justin Bieber's Exciting Announcement

\begin{tabular}{|c|c|}
\hline $\begin{array}{c}\text { Teks Sumber } \\
\text { (TSu) }\end{array}$ & $\begin{array}{c}\text { Teks Sasaran } \\
(\mathrm{TSa})\end{array}$ \\
\hline "You spent your & "Kau merayakan \\
\hline $18^{\text {th }}$ birthday on the & ulang tahun yang ke- \\
\hline show, and I gave & 18 di acara ini, dan \\
\hline $\begin{array}{l}\text { you a car for your } \\
18^{\text {th }} \text { birthday," }\end{array}$ & $\begin{array}{l}\text { saya memberimu } \\
\text { sebuah mobil waktu } \\
\text { itu," }\end{array}$ \\
\hline
\end{tabular}

Dialog ke-lima diambil dari video yang berjudul “Justin Bieber's Exciting Announcement" (The Ellen Show, 2016). Dari video berdurasi 3 menit 31 detik tersebut, tampak Justin Bieber hadir sebagai bintang tamu di acara Ellen, dan di awal video, mereka berbincang perihal kehadiran Justin Bieber sebelumnya di acara yang sama. Dari transkrip di atas, Ellen berbicara tentang perayaan ulang tahun Bieber yang ke-18 tahun, dan ia juga menyinggung perihal kado mobil yang ia berikan untuk Bieber. Terjemahan di atas adalah sepadan karena tidak ada konteks makna yang lepas ketika diterjemahkan dari bahasa sumber ke dalam bahasa sasarannya. Kesepadanan yang digunakan adalah kesepadanan formal di mana penerjemah tetap mempertahankan aspek bentuk dan isi pesan dari pernyataan di atas, tanpa adanya parafrasa.

\section{SIMPULAN}

Dari pembahasan data pada bagian sebelumnya di atas, dapat dilihat bahwa pada dasarnya mahasiswa sudah mampu menghasilkan penerjemahan yang sepadan. Banyak hal yang melatarbelakangi kemampuan mahasiswa menghasilkan terjemahan yang sepadan tersebut, seperti mahasiswa telah mempelajari konsep dasar penerjemahan di matakuliah terdahulu sehingga mereka sudah mengetahui bahwa terjemahan yang berterima di bahasa sasaran merupakan terjemahan yang sepadan dan pesan yang ingin disampaikan tercapai.

Kebanyakan hasil terjemahan mahasiswa tergolong ke dalam kesepadanan formal karena kesepadanan ini merupakan bentuk kesepadanan mendasar yang sudah pasti dilakukan oleh seorang penerjemah. Seperti yang telah disebutkan pada bagian sebelumnya, kesepadanan formal cenderung berfokus kepada kesamaan bentuk dan isi pesan. Sedangkan kesepadanan dinamis tidak terlalu sering digunakan oleh mahasiswa karena kesepadanan jenis ini biasanya dilakukan apabila seorang penerjemah 
ingin lebih berfokus kepada aspek kewajaran ekspresi dari bahasa sumber ke dalam bahasa sasaran. Teknik penerjemahan yang biasa digunakan untuk kesepadanan jenis ini adalah parafrasa karena penerjemah mengubah bentuk kata atau frasa agar pembaca sasaran bisa langsung memahami maksud atau isi pesan.

\section{DAFTAR PUSTAKA}

ABC News. (2014, 15 Desember). Taylor Swift Barbra Walters Interview: Barbra Walters Most Fascinating People [Video]. https://youtu.be/PTFhUq3otQ.

Aveline, R.G.Z. (2015). Subtitling Strategies and Translation Readibility of the Indonesia Subtitle of Maleficent Movie. Semarang: Semarang State University.

Bassnett, Susan. (2002). Translation Studies. New York: Routledge.

Catford, J.C. (1965). A Linguistic Theory of Translation. London: Oxford University Press.

Hatim, Basil, Jeremy Munday. (2004). Translation: An advanced resource book. New York: Routledge.

Hoed, Benny H. (2006). Penerjemahan dan Kebudayaan. Jakarta: PT. Dunia Pustaka Jaya.
Machali, Rochayah. (2009). Pedoman Bagi Penerjemah. Jakarta: PT Mizan Pustaka.

Munday, Jeremy. (2008). Introducing Translation Studies: Theories and Application. London: Routledge.

Nida, Eugene A., Charles R. Taber. (1974). The Theory and Practice of Translation. Netherlands: E.J. Brill, Leiden.

Nord, Christiane. (1997). Translating as a Purposeful Activity: Functionalist Approached Explained. Shanghai: Shanghai Foreign Language Education Press.

Senja, Kharisma. (2015). Subtitling Strategies of Slang Expressions in the English and Bahasa Indonesia 'Good Will Hunting' Movie Texts. Yogyakarta: State University of Yogyakarta.

TheEllenShow. (2016, 5 Desember). Justin Bieber's Exciting Announcement [Video]. https://www.youtube.com/ watch?v=1wTYZoQ-DJQ\&t=4s.

The Tonight Show Starring Jimmy Fallon. (2012, 29 Juni). Ew with Jimmy Fallon and Channing Tatum (Late Night with Jimmy Fallon [Video]. https://youtu.be/sIhU3mQTp1 U. 